\title{
A framework for assessing the commons qualities of citizen science: comparison of five digital platforms
}

\author{
Mayo Fuster Morell [1], Anna Cigarini [2,3, ${ }^{*}$, Enric Senabre Hidalgo [4]
}

[1] Berkman Klein Center for Internet and Society, Harvard University, Cambridge, 02138 MA, USA

[2] Internet Interdisciplinary Institute, Open University of Catalonia, Barcelona, 08018 Catalonia, Spain

[3] Department of Condensed Matter Physics, University of Barcelona, Barcelona, 08028 Catalonia, Spain

[4] Université de Paris, INSERM U1284, Center for Research and Interdisciplinarity (CRI), Paris, France

[*] Corresponding author annacigarini@uoc.

\begin{abstract}
Citizen Science (CS) has expanded as a collaborative model of knowledge co-production, also outside traditional scientific institutions. However, CS potential to enable new forms of collective governance of scientific research remains largely unexplored. At least, two confronting standpoints dominate debates around CS: from crowdsourcing perspectives supported by debates over cost-effectiveness of massive data collection, to more participatory views, which understand CS as a means to challenge current academic structures. In particular, the discussion around CS governance mechanisms that go beyond crowdsourcing models is still unfolding. Understanding CS as contributing to constitute science as a commons requires specific conditions that must be met. This study provides a framework for exploring the commons-related dimensions that characterize CS initiatives, as already applied in the study of commons-based peer production. It considers openness at the governance level, open knowledge at technological and data levels, and also social responsibility and impact of CS projects. The framework is tested and informed empirically with the analysis of 5 digital mapping CS projects. Data was gathered through web collection, based on a netnographic method. The results show that, overall, the dimensions considered prove useful to shed light on the commons-like formations that characterize CS. The results further point to the interplay of several institutional, legal, and practical dimensions in constructing and governing openness in CS. This preliminary adaptation of the framework is intended to place in an analytical context the debate around current challenges of both participatory science governance and public involvement in research initiatives.
\end{abstract}

\section{Introduction}

After the early cases of open source projects and platforms like Wikipedia, an online collaborative and distributed model of production and consumption has rapidly expanded (Benkler, 2006). In the sphere of research and knowledge production, citizen science (CS) has emerged as a collaborative model for generating knowledge through public engagement in scientific research, where citizens can actively contribute to science either with their intellectual effort or with tools and resources. Although not new in the 
history of science (Strasser et al., 2018), CS was brought to the fore by the advent and rapid development of digital and sensor technologies, which paved the way for new modes of knowledge creation and sharing (Newman et al., 2012). CS is contributing empirical knowledge in scientific (Kullenberg \& Kasperowski, 2016), educational (Phillips et al., 2019; Bonney et al., 2016), and sustainability terms (Sauermann et al. 2020).

Whilst rapidly evolving, however, CS is still an emerging paradigm characterized by some major dilemmas and vivid discussions. The term 'citizen science' covers indeed a very broad variety of practices and approaches, online platform models and different levels of openness to community involvement (Eitzel et al., 2017). In particular, one can distinguish between different participatory logics behind CS, from more crowdsourcing views, supported by debates over cost-effectiveness of massive data collection (Del Savio et al., 2016), to more participatory views, which understand CS as a means to challenge current academic structures and promote citizens participation in decision-making on scientific-technological issues (Irwin, 1995). Yet, there's a lack of extensive accounts in the literature about cases where "extreme" participatory CS and co-creation take place regarding the full palette and dimensions of the research cycle, beyond crowdsourced participation (Skarlatidou et al., 2019; English et al., 2018). Also, unlike the established systems of science, CS projects follow different organizational dynamics, usually online and/or outside of scientific institutions. Yet, compared to other types of online collaborative initiatives, CS usually integrates individual contributions into common knowledge pools, which can heighten interdependencies and the need for coordination and governance. Therefore, it is still unclear what are the technological configurations and knowledge policies for regulating the new roles, boundaries and relationships between researchers and research participants that CS entails (Resnik, 2019).

Further, relevant efforts have been devoted to typify and guide sustainable CS practices in terms of project development (Wiggins \& Crowston, 2011; Bonney et al., 2009), participatory logics (Haklay 2013; Bonney et al., 2009); regulatory oversight mechanisms (Cooper et al. 2019); platform design and data governance aspects (Kosmala et al. 2016; Wiggins et al., 2018); and evaluation assessments (Kieslinger et al. 2018; Phillips et al., 2019), among others. However, a holistic framework which integrates the transversal values of openness into the governance, technological and impact levels of CS projects is still missing. The lack of a careful account of the different connotations behind openness and participation that characterize CS practices might undermine the 'science democratization' promise that CS puts forward (Strasser et al., 2018), eventually creating disappointment or conflict among both participants and scientists who join CS projects (Riesch and Potter, 2014). For this, an alternative holistic approach to highlight and address some of the tensions that CS is currently facing, which may undermine its governance, quality and sustainability as a promising research practice, can be studied in connection with the commons paradigm (Kloppenborg et al., 2021; Pelacho et al., 2021; Weber et al., 2019; Madison, 2014).

\section{Citizen science and the commons}

Commons are natural and cultural resources accessible as public goods and held in common by a self-governed community, not necessarily owned privately or provided by the state (Benkler, 2006; Fuster Morell, 2010a; Ostrom, 1990). The commons approach tends to highlight a combination of several features, which include: more distributed and networked forms of property and organization; direct involvement of actors; orientation to the preservation of resources in the long term; expanding the idea of wealth (considering a broader idea of value than market price) (Bollier, 2008). Depending on the given perspective, the approach to the commons can be more focused on the property system or on the social "community" system generated around it. Commons have existed as important institutions for natural resource management in traditional, rural and communal life, as well as for the management of knowledge and information assets (Ostrom, 1990; Hess \& Ostrom, 2003). In the last decades research on the commons has 
especially developed in other contexts intensively dependent on knowledge, creativity, and innovation such as those impacted by the Internet and digital revolution (Castells \& Cardoso, 2006; Castells, 1996). During the 2000s, further contributions have enlarged the evidence and understanding about the emergence of unconventional forms of collaborative production, with studies inspired by the unexpected success of initiatives like Free/Libre and Open Source Software (FOSS or FLOSS) and Wikipedia (Ortega, 2008; Benkler, 2002; Weber, 2005).

Partly relying on the work on the traditional commons developed by the 2009 Nobel Laureate Elinor Ostrom (1990), Commons-Based Peer Production (CBPP) was proposed as a concept for describing forms of production in which, through the Internet, large-scale contributions and creativity are pooled and coordinated into collaborative projects without relying on traditional hierarchical organisations or monetary exchanges and rewards (Benkler, 2006). CBPP theory has been developed further by other authors (e.g. Aigrain, 2012; Bollier, 2008) as a framework to understand new productive and collaborative activities that take place online, outside the logics of market and state, with characteristics such as: openness to participation (Fuster Morell, 2010a); strong inequality in the distribution of the contributions among the whole community (Ortega, 2008); decentralization (Crowston \& Howison, 2005); modularity and granularity (Benkler, 2006); no coercivity and coordination based on stigmergy (Siefkes, 2011); transparent process (Bauwens, 2007); intellectual communal property (Wark, 2004); and value dimensions beyond monetary conceptions (Fuster Morell, 2016).

Overall, extensive literature has thus identified the institutional features and governance factors that allow the flourishing of the commons, as well as the challenges that lay ahead. Meanwhile, there has been an expansion of CBPP to areas of activity other than the initial ones, as is the case for CS. In particular, CS and CBPP share some fundamental principles: both build on the collaborative effort of a network of volunteers which produce and share non-rival resources, are strongly reliant on technological infrastructures, are not for-profit in scope but rather show a strong social, sustainability and pro-democratic focus. Commons' concepts and principles may thus help to overcome some dilemmas that CS is facing. It is not clear whether current CS approaches transcend the epistemic authority of traditional scientific institutions, or rather restrict participation to more mundane tasks. The question remains also as to how to govern and coordinate the contribution of nonprofessional scientists into knowledge co-creation. Nor is clear whether and how CS projects could expand in terms of both participation and complexity while maintaining democratic principles. Understanding CS as a commons may thus constitute a model or at least an inspiration for defining the conditions required for the sustainability, accessibility and quality of scientific knowledge produced through citizens participation. Yet little research has drawn a direct link between CS and the commons, focusing on the transversal values of openness of CS as a way to connect at the theoretical level current challenges of both science governance and public participation. Therefore, empirical evidence of the potential of commons-oriented CS practices remains limited, fragmented and inconclusive. To what extent are CS digital platforms following CPBB principles? What are the governance models, knowledge and technological policies, and the impacts and social responsibilities embedded in CS digital platforms?

The objective of this study is to explore the overlaps between CS and CBPP by adapting to the CS context a novel analytic framework, already applied in the study of peer-to-peer production models. In particular, the analysis aims to assess the commons' qualities of CS practices with a focus on openness at the governance, technological and impact levels. Given the heterogeneity and dynamism of CS, the analysis has more to do with mapping a plural "ecosystem" rather than drafting a two-sided field with a clear line of "delimitation" of what commons' oriented CS practices are, and what they are not. The aim is thus to survey the diversity of CS typologies, and the various ways in which commons' oriented CS models could differ from other models, taking into account how CS projects formalize both inputs and outputs of collaborative scientific production initiatives. 


\section{Defining the commons qualities of citizen science}

The commons qualities of CS are analyzed through the lenses of an adapted version of the Multidisciplinary Balance of Platform Economy framework from Fuster Morell \& Espelt (2019). The original framework was informed by a multidisciplinary analysis and state of the art of the commons studies of the Ostrom school, which point to the principles of successful community governance of collective resource systems, as well as on cooperativism principles, which stress the link between community governance and the underlying economic infrastructure. The framework further draws on cyber scholar's work (Benkler, 2006; Lessig, 2002; Rose, 1986) around the role of openness, decentralization and net neutrality for sustainable technological infrastructures and policies. It draws also on social justice theories, which emphasize the importance of inclusion, equity and social responsibility for transforming resources and practices to serve the welfare of the community (Ostrom, 1990). The framework's commons' balance covers the governance, economic model, technological and knowledge policies, and the impact and social responsibility of CS platforms (Fuster Morell \& Espelt, 2019). It can help to visualize the commons' qualities of collaborative digital initiatives, differentiate models, provide insights for the sustainability of their design, and inform its technological development. It has been applied to the analysis of the platform economy ecosystem in Barcelona (Spain) (Fuster Morell \& Espelt, 2019); to explore how the sustainable design of a platform economy could contribute to the Sustainable Development Goals (Fuster Morell et al., 2020); and to survey the qualities, practices and evolution of urban food networks (Moreira \& Fuster Morell, 2020).

Compared to its prior applications, however, this study incorporates novel indicators specific to the CS context. In particular, it includes perspectives from action research, co-creation and RRI literature (Senabre Hidalgo \& Fuster Morell, 2019) that address openness at the level of the research process, in terms of both inputs (how open is the level of interaction and decision-making) and outputs (taking into account research ethics and non conventional research impacts). It further specifies the impact sub-dimension (Kieslinger et al., 2018), in terms of conventional scientific outputs, as well as CS potential to address sustainability problems and also influence policy and action (Sauermann et al. 2020). The adapted version of the framework is articulated around 6 commons' qualities: Research governance, Institutional governance, Knowledge policy, Technological policy, Impact, and Social responsibility (Table 1). 


\begin{tabular}{|c|c|c|c|c|c|}
\hline Dimension & $\begin{array}{l}\text { Sub- } \\
\text { dimension }\end{array}$ & Indicator & Fulfillment & Partial fulfillment & Unfulfillment \\
\hline \multirow{5}{*}{ GOVERNANCE } & \multirow[b]{2}{*}{ RES GOV } & Research openness & $\begin{array}{l}\text { Participation throughout all steps of } \\
\text { the research process }\end{array}$ & $\begin{array}{l}\text { Participation in some steps of the } \\
\text { research process }\end{array}$ & $\begin{array}{c}\text { No participation is possible } \\
\text { beyond data collection }\end{array}$ \\
\hline & & Transdisciplinarity & $\begin{array}{l}\text { Features that favour scoping, } \\
\text { methods and applicability that } \\
\text { transcend disciplinary boundaries }\end{array}$ & $\begin{array}{l}\text { Some features that transcend } \\
\text { disciplinary boundaries }\end{array}$ & $\begin{array}{l}\text { No features that transcend } \\
\text { disciplinary boundaries }\end{array}$ \\
\hline & \multirow{3}{*}{ INST GOV } & Type of organization & $\begin{array}{c}\text { Procommon organization (i.e. public } \\
\text { university) }\end{array}$ & $\begin{array}{c}\text { Democratic governance (i.e. } \\
\text { foundation, association, cooperative) }\end{array}$ & Private company \\
\hline & & Sustainability model & Non-profit & Pro-public & Profit \\
\hline & & Economic transparency & $\begin{array}{l}\text { Any member can access the } \\
\text { project's economic information }\end{array}$ & $\begin{array}{l}\text { Some economic information is } \\
\text { available }\end{array}$ & $\begin{array}{c}\text { No economic information is } \\
\text { available }\end{array}$ \\
\hline \multirow{4}{*}{$\begin{array}{l}\text { KNOWLEDGE AND } \\
\text { TECHNOLOGICAL } \\
\text { POLICY }\end{array}$} & \multirow{2}{*}{ KNOWL } & Open data & $\begin{array}{c}\text { Data is downloadable and open to } \\
\text { reuse }\end{array}$ & $\begin{array}{l}\text { Data can be accessed with } \\
\text { restrictions (i.e. request form) }\end{array}$ & $\begin{array}{l}\text { No data is downloadable } \\
\text { and open to reuse }\end{array}$ \\
\hline & & Content license & Content licenses are mainly copyleft & Part of the contents are open access & $\begin{array}{l}\text { All rights of contents are } \\
\text { reserved }\end{array}$ \\
\hline & \multirow[b]{2}{*}{ TECH } & FLOSS & All tech tools are based on FLOSS & Some tech tools are based on FLOSS & $\begin{array}{l}\text { No tech tools are based on } \\
\text { FLOSS }\end{array}$ \\
\hline & & Decentralization & $\begin{array}{l}\text { Tech architecture is decentralized } \\
\text { (i.e. the software can be federated } \\
\text { and/or hosted in different servers) }\end{array}$ & $\begin{array}{l}\text { Tech architecture is partially } \\
\text { decentralized }\end{array}$ & $\begin{array}{l}\text { Tech architecture is } \\
\text { centralized }\end{array}$ \\
\hline \multirow{6}{*}{ EFFECTS } & \multirow{3}{*}{ IMPACT } & Research outputs & $\begin{array}{l}\text { Derived scientific publications are } \\
\text { available on the platform }\end{array}$ & Some research output is available & $\begin{array}{l}\text { No research output is } \\
\text { available }\end{array}$ \\
\hline & & Environmental impact & $\begin{array}{c}\text { Promotion of initiatives or features } \\
\text { that favour environmental impact } \\
\text { reduction }\end{array}$ & $\begin{array}{l}\text { Some features that favour } \\
\text { environmental impact reduction }\end{array}$ & $\begin{array}{l}\text { No features that favour } \\
\text { environmental impact } \\
\text { reduction }\end{array}$ \\
\hline & & Policy impact & $\begin{array}{l}\text { Promotion of initiatives or features } \\
\text { that favour evidence-based policies }\end{array}$ & $\begin{array}{l}\text { Some features that favour evidence- } \\
\text { based policies }\end{array}$ & $\begin{array}{l}\text { No features that favour } \\
\text { evidence-based policies }\end{array}$ \\
\hline & \multirow{3}{*}{ SOC } & Inclusion & $\begin{array}{c}\text { Promotion of initiatives or features } \\
\text { that favour inclusion of socially } \\
\text { disadvantaged groups }\end{array}$ & $\begin{array}{l}\text { Some features that favour inclusion } \\
\text { of socially disadvantaged groups }\end{array}$ & $\begin{array}{l}\text { No features that favour } \\
\text { inclusion of socially } \\
\text { disadvantaged groups }\end{array}$ \\
\hline & & Gender equality & $\begin{array}{c}\text { Promotion of initiatives or features } \\
\text { that favour gender equality and } \\
\text { awareness of care }\end{array}$ & $\begin{array}{l}\text { Some features that favour gender } \\
\text { equality and awareness of care }\end{array}$ & $\begin{array}{l}\text { No features that favour } \\
\text { gender equality and } \\
\text { awareness of care }\end{array}$ \\
\hline & & Participants rights & $\begin{array}{l}\text { Promotion of initiatives or features } \\
\text { that protect participants rights (i.e. } \\
\text { code of conduct) }\end{array}$ & $\begin{array}{l}\text { Some features that protect } \\
\text { participants rights }\end{array}$ & $\begin{array}{l}\text { No features that protect } \\
\text { participants rights }\end{array}$ \\
\hline
\end{tabular}

Table 1. Indicators of procommons qualities of citizen science digital platforms. Framework dimensions, sub-dimensions and indicators adapted from the Multidisciplinary Balance of Platform Economy framework (Fuster Morell \& Espelt, 2019).

\section{Governance}

Governance refers both to the way the platform is governed at the institutional level, and to the level of openness throughout the research process itself. Research governance covers: (i) the level of community engagement, namely whether the project adopts early participatory mechanisms or a co-design approach, for example integrating users' feedback through, i.e. online/physical community meetings or surveys, compared to whether participation is allowed at the later stages of implementation, usually restricted to data collection tasks (Research openness); and (ii) to the availability of platform features or initiatives that favour scoping, methods and applicability transcending disciplinary boundaries, in terms of integrating a diversity of not only experts from different paradigm-perspectives and affiliations, but also from other areas of human knowledge connected to participant's skills, culture and / or identity (Transdisciplinarity). Governance at the institutional level refers to the economic orientation and sustainability of the platform, and its underlying economic model. In particular: (i) Type of organization refers to the economic enterprise or legal entity of the platform; (ii) Sustainability model refers to the type of resources used in the platform's financial models; (iii) Economic transparency refers to accessibility of the platform's economic information.

\section{Knowledge and technological policy}

Knowledge and technological policy refers to both the technological tools and licenses that are adopted, and the way the platform promotes the creation or improvement of specific areas of knowledge. More specifically, two elements of knowledge policy are considered: (i) Open data \& publications refers to the accessibility (namely the possibility to export copy or access content, under specified governance rules) of all or parts of the data generated by users and the final research outputs through the platform strategic design; (ii) Content license refers specifically to the level of openness of user-generated content license models adopted by the platform. Technological policy, on the other hand, refers to the openness of the technological 
architecture and the software adopted. In particular: (i) FLOSS refers to whether the technological infrastructure is less open or more open, considering whether the platform is developed in a Free/Libre and Open Source Software (FLOSS) environment; (ii) Decentralization, finally, covers whether the technological infrastructure is distributed as peer-to-peer, federated or centralized. In other words, if the platform as a digital affordance is not only replicabe according to the previous criteria derived from FLOSS principles, but also allows to federate it or connect in some ways to other platforms or initiatives.

\section{Derived effects}

Derived effects relate to the direct impact and social value that the platform tries to generate, and to the level of awareness and responsibility regarding unintended or negative consequences of its use. More specifically, impact includes conventional scientific outputs such as research articles reporting new knowledge, but also more qualitative indicators of research impact, such as influence on policy-making and social practices. The options we attempted to explore are: (i) Research outputs, which refers to the availability on the platforms of academic peer-reviewed publications or other type of scientific or research-derived reports, like preprints, white papers, etc.; (ii) Environmental impact refers to the impact of the platform on the natural environment, in terms for example of biocultural conservation actions or environmental-justice outcomes; (iii) Policy impact refers to the wider platform's influence on policy and institutional or formal practices, in terms for example of derived policies, toolkits, methods or learning processes. Social responsibility, on the other hand, refers to the social value that the platform tries to generate or embeds. In particular: (i) Inclusion refers to whether the platform has significant features and/or policies to favour diversity of participation and the inclusion of marginalized or in-risk collectives; (ii) Gender equality refers to whether the platform favours gender equality and awareness of care in terms of access to and participation in the platform (i.e. adopting a gender perspective in its communication strategy or content production); (iii) Participants rights refers to whether the platform includes a code of responsible conduct and clearly communicate about authorship, privacy and ownership issues.

On the basis of this study, as defined above, guided by the adoption and adaptation of the commons balance (Fuster Morell \& Espelt, 2019), commons-oriented CS practices can thus be observed as a tendency, a set of qualities, and a modality of collaborative science - regarding both the design and the performance of the whole process, and characterized by a defined and integrated approach regarding the dimensions of governance, technological base and derived effects of CS platforms. In this regard, it is also important to mention, as a summary of guiding principles that can contribute to these integral commons-oriented CS practices, that they can be characterized by: 1) favouring peer to peer relations and the involvement of the community of citizen scientist in the project's governance; 2) profitability is not the main driving force of the initiative, which aims instead at economic sustainability, transparency and accountability; 3) as an open and a privacy-aware civic infrastructure, derived results and resources promotes access, reproducibility and derivativeness; 4) responsibility regarding the effects generated by the process results in a diversity of internal awareness and policies for respecting both the community and the natural environment.

\section{The case of digital mapping projects}

This adapted framework is discussed based on a comparative analysis of the commons' qualities of five existing CS platforms. For the sake of comparison, and to overcome the highly heterogeneous nature of CS practices, the analysis focuses specifically on digital mapping projects. Digital mapping CS projects usually rely on digital tools to collect, analyze, and share geographic information provided by individuals using mapping systems, on an often more spatially and temporally extensive scale than traditional geographic mapping approaches (Haklay, 2010). 
The 5 digital mapping CS platforms for our study were selected according to the following criteria: (1) First and foremost, existing projects that broadly comply with the ECSA 10 Principles of Citizen Science (European Citizen Science Association, 2015); (2) Projects based on collective mapping that make use of a digital platform for (at least) data collection; (3) Initiatives which are not in their early stage development (with at least 5 years of activity); (4) Heterogeneity in terms of scope, historical background and participatory formats. Further criteria considered for the sample selection was the presence of sufficient project-related scientific and grey literature for reference. The resulting projects sampled are (in alphabetical order): eBird, GeoWiki, iNaturalist, Public Lab, and Safecast.

- eBird (https://ebird.org/home) is a CS platform that allows users to collect and access data on bird abundance and distribution at a variety of spatial and temporal scales. eBird was launched in 2002 by the Cornell Lab of Ornithology at Cornell University and the National Audubon Society, mainly inspired by the ÉPOQ database, with the aim to maximize the utility and accessibility of the vast numbers of bird observations made each year by recreational and professional birders.

- GeoWiki (https://www.geo-wiki.org/) is a CS platform for environmental (biophysical and socioeconomic) monitoring. More specifically: GeoWiki data documents global agricultural field-size, global built-up surface layer, or human impact on forests. GeoWiki was established in 2009 at the International Institute for Applied Systems Analysis (IIASA) for the validation and collection of new geographical information through crowdsourcing. Its scope is to improve the availability of global cropland information with higher accuracy, resolution and coverage compared to similar information sources.

- iNaturalist (https://www.inaturalist.org/) is a CS platform for biodiversity monitoring. iNaturalist.org began in 2008 as a Master's final project at the UC Berkeley School of Information, becoming now a joint initiative between the California Academy of Sciences and the National Geographic Society. The platform is addressed to naturalists, citizen scientists and biologists, built on the concept of mapping and sharing observations of biodiversity across the globe

- Public Lab (https://publiclab.org/) is a CS platform for open source environmental research that supports communities facing environmental justice issues, such as increased flooding, poor air quality, pollution and destruction of wetlands, in a "do-it-yourself" approach to environmental monitoring and advocacy. Public Lab grew out of a grassroots effort to take aerial photographs of the BP Oil Spill in the Gulf of Mexico in 2010.

- Safecast (https://safecast.org/) is a CS platform for ionizing radiation mapping (and lately for mapping COVID-19 official testing options). Safecast was established shortly after the Fukushima Daiichi nuclear disaster in Japan, following the Tōhoku earthquake in March 2011. It grew out due to the unavailability of accurate and trustworthy radiation information regarding those event, with the aim of providing the public with actionable data about their environments.

Data collection for this study was based on a codebook (MacQueen et al., 1998) derived from the presented framework, and it took place between June and October 2020. One researcher (A.C.) collected the data on all 5 CS platforms, and another researcher (E.S.H.) independently collected data on 2 CS platforms. The results were then compared and discussed for reliability checks.

The methodological approach builds on a nethnographic analysis of the CS platforms features and public content available. Netnography is an ethnographic technique broadly applied to the study of online communities and web platforms, which allows to capture and reflect properties and communications in digital settings through an observational, inductive and unobtrusive approach (Kozinets, 2010). It is grounded in digital methods which focus on how digital tools shape information flows, how users make use of digital environments, and how social configurations and shared identities emerge (Whitehead \& Wesch, 2009). CS platforms are thus understood as social spaces which are structured around networked 
technologies and the shared identities resulting from the interaction of people, technology and practice (Latour, 2007). The qualitative analysis further builds on the authors' iterative discussion about the framework's indicators for each project sampled.

\section{Comparing commons qualities across digital mapping projects}

We present and discuss below the analytical framework of the commons' qualities of CS projects based on the selected sample of 5 digital mapping CS platforms: eBird, GeoWiki, iNaturalist, Public Lab and Safecast (Figure 1).

\begin{tabular}{|c|c|c|c|c|c|c|c|}
\hline Dimension & $\begin{array}{l}\text { Sub- } \\
\text { dimension }\end{array}$ & Indicator & eBird & GeoWiki & iNaturalist & Public Lab & Safecast \\
\hline \multirow{5}{*}{ GOVERNANCE } & \multirow{2}{*}{ RES GOV } & Research openness & & & & & \\
\hline & & Transdisciplinarity & & & & & \\
\hline & \multirow{3}{*}{ INST GOV } & Type of organization & & & & & \\
\hline & & - Sustainability model & & & & & \\
\hline & & Economic transparency & & & & & \\
\hline \multirow{4}{*}{$\begin{array}{l}\text { KNOWLEDGE } \\
\text { AND } \\
\text { TECHNOLOGICAL } \\
\text { POLICY }\end{array}$} & \multirow{2}{*}{ KNOWL } & Open data & & & & & \\
\hline & & Content license & & & & & \\
\hline & \multirow{2}{*}{ TECH } & FLOSS & & & & & \\
\hline & & Decentralization & & & & & \\
\hline \multirow{6}{*}{ EFFECTS } & \multirow{3}{*}{ IMPACT } & Research outputs & & & & & \\
\hline & & Environmental impact & & & & & \\
\hline & & Policy impact & & & & & \\
\hline & \multirow{3}{*}{ SOC } & Inclusion & & & & & \\
\hline & & Gender equality & & & & & \\
\hline & & Participants rights & & & & & \\
\hline
\end{tabular}

Figure 1. Comparative analysis of the commons qualities of the digital mapping projects: eBird, GeoWiki, iNaturalist, Public Lab and Safecast.

\section{Governance}

\section{Research governance}

In the cases sampled, CS digital platforms do present features that allow to integrate community feedback throughout the project development process. In eBird community participation serves primarily data collection tasks, namely the collection of bird observations. In Safecast, however, volunteer citizen scientists can interact through online discussion groups or organizing events like hackathons. The GeoWiki community can participate through annual campaigns, by following and interacting in a Facebook group, or through contributing data by making use of a number of GeoWiki apps (Picture Pile ${ }^{1}$, Natura Alert ${ }^{2}$, Fotoquest Go ${ }^{3}$ ). iNaturalist allows users to start their own projects using the core iNaturalist search tools, data visualizations and leaderboards. This feature allows potential project leaders to run a "bioblitz" (a public event that focuses on finding and identifying as many species as possible in a specific area over a short period of time, usually 24 hours), as well as track and display a set of observations made within a specific location or group, and to communicate with project participants. The platform also provides a community forum to interact with other

\footnotetext{
${ }^{1}$ https://geo-wiki.org/games/picturepile/

${ }^{2}$ https://natura-alert.net/

${ }^{3}$ https://fotoquest-go.org/en/
} 
users, report bugs, and request new features. Alternatively, iNaturalist volunteers can engage by simply collecting and uploading observations. Public Lab has the strongest participatory and co-design approach: allowing for different levels of participation to coexist, from amateurs, community members, community moderators, to staff, organizers or sponsors. In Public Lab local environmental questions are provided by local-residents living nearby, and can be explored with tools that are low cost and easy to use and replicate. Participation is open through the project's website, the online forums, and in-person events or strategic retreats, and individuals can contribute from designing the research question and building the knowledge base, to creating the website itself, as well as actively developing and modifying the research tools. Ways of interacting in Public Lab builds also on activity grids on tool pages, a "Question/Answer" feature that helps participants to interact and share information, and online community meetings where people can collaborate, such as weekly and monthly open calls. Beyond merely collecting or analyzing data, participation in CS can take a number of forms and include a social component like sharing interests, contribute stories, and collective learning (Liberatore et al., 2018), or more passive engagement, like looking at or sharing content without making contributions as found, for example, in the Wikipedia community (Fuster Morell, 2010b). Yet, all forms and degrees of participation count, in terms of producing and reproducing knowledge because of codependencies, feedbacks, adaptations, and synergies (Fuster Morell, 2010b). In this sense, digital technologies play a key role in shaping individual contributions, by also providing the settings for cultivating online communities of practice (Liberatore et al., 2018) to support dispersed groups of volunteers.

Also, extensive evidence in CS seems to suggest that the majority of CS projects take place in biology, conservation, ecology, or in geographic information research, with little application of CS in the social sciences and humanities as compared to environmental issues and health (Kullenberg \& Kasperowski, 2016). Few CS projects adopt a transdisciplinary formulation that favours scoping, methods and applicability that transcend disciplinary boundaries, reflecting how cross-disciplinary debates and approaches are gaining increasing ground within the CS community (Tauginiene et al., 2020). Indeed among the cases sampled only Public Lab seems to favour some kind of transdisciplinary approach, in terms of integrating personal and local knowledge. In Public Lab's spectrometry project, for example (https://publiclab.org/tag/spectrometry), which originally aimed at exploring questions such as "Can I tell if this sample contains petrochemical oils?", participants have built and used spectrometers that look different and explored all kinds of other questions, such as food oil fraud or the presence of organophosphate pesticides. In this sense, the project specifically calls for inputs from a broad range of expertises including activists, makers, scientists, technologists and other curious people.

\section{Institutional governance}

None of the analysed platforms is based on economic transactions and no economic returns are displayed. However, the cases sampled do not seem to favour transparency in terms of publicly displaying information about the type and redistribution of the projects' financial resources (except for Public Lab). The lack of, for example, a dedicated project page that informs on the project's economic sustainability points to the potential of transparency and accountability for challenging confusion, distrust or misconceptions surrounding CS. According to the public information available for analysis, eBird, GeoWiki and iNaturalist are mainly university-driven projects, while Public Lab and Safecast can be characterised as civic initiatives (more concretely, constituted as non-profit organizations). In the case of eBird, sustainability seems to be based on individual donations, grants and sponsors. iNaturalist sustains itself through individual and charity donations, merchandising and grant funds. Public Lab, organized as a global community with offices in several U.S. states, is primarily funded through philanthropic grants and revenue from do-it-yourself kit sales (https://store.publiclab.org/). This allows the creation of online infrastructure for communities to utilize, seed and steer tool development, as well as providing funding sources for supporting community projects. Finally, Safecast sustains itself mainly through individual donations and international grants. As already reported (Wiggins \& Crowston, 2014), this aligns with the fact that CS projects are likely to rely on a combination of 
funding sources which range from institutional support to private donations, which can increase the project's sustainability compared to relying on a single source of funding.

\section{Knowledge and technological policy}

\section{Knowledge policy}

Data and knowledge resources generated through public participation represent the foundation of CS, often recognised as an important aspect of the open science agenda (Mirowski, 2018). However, recent evidence suggests that CS projects are sometimes failing to provide open access to research outputs and/or in proper formats (Bowser et al., 2020; Groom et al., 2017). What is unique to CS is, indeed, that the community of citizen scientists has an active stake in the production of data as co-producers (not only as taxpayers, as in the open access debate), which highlights extra ethical and legal challenges for knowledge access and reuse (Riesch \& Potter, 2014). At the same time, open data practices and data management policies may help to prevent misconceptions regarding data sharing (Bowser et al., 2020), increase project's success (Theobald et al., 2015), and motivate initial, continued, and renewed engagement in CS projects (De Vries et al., 2019). A crucial element for favouring data access and reuse is to implement explicit data management policies (Bowser et al., 2020) with standard licences and no restrictions on commercial usage, but requiring attribution and 'share alike' formats (Groom et al., 2017). Regarding its content license criteria, each platform has different licenses and terms and conditions with varying degrees of openness. In particular, for audiovisual material eBird does not adopt a Creative Commons license, therefore using eBird images requires consent from the eBird user who uploaded the media. However, eBird states that it is considering introducing more liberal licences, to allow users to choose a licence so that anyone can use their images without contacting eBird or the photographer. GeoWiki broadly uses a Creative Commons Attribution-NonCommercial-ShareAlike license (CC BY-NC-SA) for user-generated content. The current default license for images uploaded to iNaturalist is the Creative Commons Attribution Non-Commercial license (CC BY-NC), though participants can opt-out of such licensing if they choose to, or select from a range of Creative Commons licences, including releasing their data into the public domain. In the case of Public Lab, content is released under both Attribution and Share-Alike licenses (CC BY-SA) and CERN Open Hardware Licenses, unless otherwise specified by the user. In Safecast all website's contents are published under a Creative Commons Attribution Non-Commercial licence (CC BY-NC) whereas data is published under a CC0 public domain designation.

As for the ability to access data generated by users, all the studied CS platforms except eBird allow the public to openly access and download scientific data provided by the community without restrictions. GeoWiki data, specifically, is available via a number of open access repositories (Pangaea, World Urban Database Data Catalog or Picture Pile data). Also, an electronic copy of the publications listed on the platform are deposited in an open access repository or openly available for download. iNaturalist data can be downloaded by registered users, with the exception of sensitive species data and private user data, but no reference to openly accessible scientific publications is available on the platform. Public Lab has developed a number of open source software platforms to assist in the collection, analysis, storage, sharing, and conversion of data from open source tools. For this, the data storage and sharing websites MapKnitter.org, SpectralWorkbench.org, and Infragram.org provide long-term storage for locally produced data, and convert and present such data in open, standard formats which are easy to use and reuse for the press, "scientists", and other advocacy groups, while providing community researchers in parallel with a forum to discuss, interpret, and compare data. In Safecast, all data is collected via the Safecast API and is presented on the publicly available interactive Safecast Tile Map. Also, the project keeps tabs on developments in Fukushima and provides open access readable summaries of important news and research such as the Safecast Report, to inform people about recent activities and advancements, as well as about the conditions at the Fukushima 
Daiichi plant itself, the environment, evacuees, food, and health. Finally, in eBird, while dynamic and interactive maps, graphs and species statistics are available on the eBird website (for registered and non-registered users), data is downloadable only for registered users after filling a data request form.

\section{Technological policy}

Data openness and/or reuse also depends on technological infrastructures (provision of freely available reusable software) and hosting platforms (low to no-cost), which are a critical element in many CS projects (Wiggins et al., 2018). Overall, all platforms except for eBird favour openness regarding the software and the technological infrastructure they rely on. In GeoWiki, the only component which is not open source is the Google Earth API. Likewise, almost all of iNaturalist software is freely available for modification by other developers, so users are allowed to add new functionalities to the website or mobile apps by opening an issue on Github or starting a topic on the iNaturalist Forum. All Public Lab technological tools are based on FLOSS, and Public Lab's open source code is also located on GitHub. As mentioned above, specific third-party data storage and sharing websites provide long-term storage for locally produced data, and convert and present that data in open, standard formats. Finally, the hardware and software developed by Safecast are also open source and available for modification by contributing developers. Safecast open source code is also located on GitHub. There, for example, the source code of the 'bgeigie' measurement device is designed to be easy for anyone to assemble. Users can buy its main components online from the Safecast website, or develop them themselves using freely available instructions and software packages. In the case of eBird, it provides access to interface protocols, and the possibility to use the "give feedback" option in the app itself to reach the project organization. Also, in eBird it is possible to get an API key to query the website, which returns data in JSON format.

As for the level of distribution of technological architecture, eBird digital infrastructure and software does not seem to favor openness and / or interoperability, since its platform is centralized and not reproducible. The general Geo-Wiki architecture is centralized but reproducible, and consists of different standard components integrated into a single portal. iNaturalist has a centralized reproducible technological architecture as well, which coordinates localized websites that are fully connected to the global iNaturalist community. This network operates as a series of separate national-scale branded gateways of the iNaturalist software, locally configured and led by partner organizations in each country. These gateways are connected with shared infrastructure that operates across the iNaturalist network. In Public Lab and Safecast the technological infrastructure model is similar in both cases, reproducible and fully distributed, namely the software can be federated or hosted on different servers.

\section{Derived effects}

\section{Impact}

Many CS projects stress contribution to science as their primary goal (Theobald et al., 2015). Especially for crowdsourcing projects, evidence has already demonstrated that CS can effectively increase the production of valuable scientific knowledge by contributing significant effort and knowledge resources (McKinley et al., 2017). Indeed, all the cases sampled except iNaturalist support participants' access to published findings by disclosing the research articles generated through public participation, which is one measure of scientific contribution. However, contributing to science is not the only goal of CS, which has over time produced a particularly dense promissory discourse (Strasser et al., 2018) and which includes a number of diverse goals such as science education (Phillips et al., 2019; Bonney et al., 2016), or community goals often related to environmental or social justice issues (McKinley et al., 2017; Wiggins \& Crowston, 2011). 
In terms of environmental awareness and impact, all the projects sampled seem to play an important role in filling data gaps for environmental monitoring and reporting, environmental awareness and education, or by facilitating the creation of environmental infrastructure for biodiversity monitoring. Since 2006 eBird data has been used in more than 60 peer-reviewed publications and reports, from highlighting the importance of public lands in conservation, to studies of evolution, climate change, and biogeography (Kelling et al. 2013). Geo-Wiki has applications in many successful CS campaigns and ongoing projects that bring together the field of earth observation and citizen participation, including several citizen "observatories". These include new research approaches such as land cover change detection, quality assurance of CS data, or supporting local food producers. iNaturalist core mission and values place a strong emphasis on creating extensive community awareness about local biodiversity, as well as promoting further exploration of local environments. Moreover, a teacher's guide is provided and accessible for educators seeking to use iNaturalist in the classroom. Furthermore, an educational tool, the Seek by iNaturalist app, has been developed as an easier alternative for young students and beginners in the use of iNaturalists. Public Lab strongly relies on inexpensive do-it-yourself techniques and prioritizing advocacy methods to increase community understanding of environmental issues. Accountability and awareness about environmental concerns are achieved through training both online and offline, as well as other education and support features, and emphasising human capacity to understand and respond to challenges. Through a wiki tool people can pose questions, post their research and reach out to others. It also includes plans and guides for do-it-yourself monitoring projects, so they can be developed from home. Everything about Public Lab seems oriented to the community and remains open source, including scientific results, technology outcomes, and generated data. Finally, Safecast's stated goal is to create useful, accessible, and granular environmental data for public information and research. For this the project facilitates the collection and sharing of environmental data through affordable devices aimed at increasing environmental and health risks awareness. Safecast maintains the largest open dataset of background radiation measurements ever collected - over 65 million readings to date, growing daily. All the data collected is available through an open, free and public map of submitted radiation and air data readings that can be accessed via browser or smartphone.

Policy impact refers, for the projects sampled, to community resilience and reaction to the lack of actionable and reliable data provided by official bodies, at times of environmental emergency for risk-related problem solving (Kenens et al., 2020: Dosemagen et al., 2011). This is especially evident for clearly open and community-driven projects such as Public Lab and Safecast, compared to the rest of analysed platforms that prioritize a crowdsourced participatory format. In particular, Public Lab's tools have been used to contest official maps regarding natural pollution disasters, enabling communities to identify affected sites or resources that are not included in official maps. Following that model in Lima, Peru, for example, members of an informal settlement developed maps of their community as evidence of their situation in relation to pollution issues, while on the Gulf Coast of the US, locally produced maps of oil-spills were used to document damage underreported by the state officials (Dosemagen et al., 2011). In this sense, Public Lab disseminates its results also as an alternative to government and corporate official information, drawing explicit attention as a grassroots community of practice by appropriating low-cost mapping. While most accounts of CS are often explained in connection with large datasets and the possibilities of mobilizing crowds outside science, in order to assist mainly with observations and classifications, there similar signs of other "modes" of CS as alternative ways of democratizing science, aiding concerned and sometimes smaller communities in collecting and analyzing data to influence a specific policy or media coverage, or as a way of promoting political decision processes about the environment and health (Berti Suman \& Van Geenhuizen, 2020; Ottinger, 2010; Irwin, 1995).

Safecast, on the other hand, has enabled people to easily monitor pollution data in their own homes and community environments, at the margin of government and other institutions. Despite high levels of public distrust in scientists, as well as the contested nature of citizenship in Japan and in nuclear energy debates, CS 
projects and interactions through Safecast have demonstrated the potential of "co-creative innovation" by providing an alternative policy discourse in Japan. One that promotes co-creative innovation across multiple communities, networks, sectors, and regions (Kenens et al., 2020). In contrast, there seems to be no evidence of derived policies or new practices, derived toolkits, derived methods or derived learning processes through the information available on the eBird, GeoWiki and iNaturalist platforms when developing our analysis.

\section{Social responsibility}

As for the projects' role in inclusion of marginalized collectives, eBird, GeoWiki, iNaturalist and Safecast do not explicitly include relevant features or strategies for favouring diversity of participation. In contrast, through open science and participatory co-creation approaches, Public Lab places a strong emphasis on empowering affected communities with tools and resources to speak substantively about their environmental concerns. Public Lab's tools are conceived as affordable, self-made and end-user modifiable, for what "how to" guidelines are offered in different languages. All these characteristics allow to define Public Lab as a socio-technological platform that builds on the idea that cost, complexity, and lack of access can prevent communities from playing an active role in research, for example documenting environmental problems.

Yet, based on all the references and platform content studied, none of the projects sampled seem to clearly approach gender equality and awareness of care, contrary to debates and practices in other online collaborative settings (Edelman \& Luca, 2014; Schor, 2014). This missing aspect stresses the importance of the gender dimension in online collaboration processes, broadly linked to handling inclusion and diversity from an intersectional perspective (considering gender with its connection to other axes of discrimination, such as race, class, and origin).

Finally, participants' privacy and digital-related rights are more or less explicitly addressed in all the platforms analyzed except GeoWiki. eBird includes a code of responsible conduct that also informs about authorship and ownership issues. iNaturalist provides a "Getting Started" guide to inform about some of the site's features, as well as a FAQ section about the project. This project also provides community guidelines, developed through extensive input from participants, to describe what is considered good and bad behavior (i.e. suspendable offenses, or occasionally contentious behaviors regarding contribution's tone and attitudes), as well as suggested good practices for civil engagement. In the case of Public Lab, the project's code of responsible conduct has been drafted collectively, providing a clear set of practical guidelines for events led by organizers and community members, participatory events, and online channels such as the website, comment threads on software platforms, chatrooms, the mailing lists, the issue tracker, and other communication spaces. Safecast offers a FAQs section informing on the source and quality of data, its goals, governance and institutional connections, as well as information on how to interpret Safecast measurements and on the implications of the evidence collected through the project's data.

\section{Discussion}

The present exploratory study represents an attempt to develop a framework for surveying the commons' qualities of CS practices. The framework, already applied in the study of peer-to-peer production models (Fuster Morell et al., 2020; Fuster Morell \& Espelt, 2019), focuses on openness at the governance, technological and impact levels. Our netnographic analysis builds on 5 digital mapping projects as running examples, at the time of data collection, to provide points of comparison and illustration that shed light on the diversity of openness and commons' qualities of CS practices. The results show that, overall, the dimensions considered in the framework can be useful to develop a broad understanding of the extent to which CS practices are following CBPP principles. Indeed, in very few cases the commons qualities examined in CS platforms during this study are neither irrelevant nor prevalent. While some projects might 
present commons' qualities in most of the governance, technological and impact dimensions, others seem to follow commons' principles in some dimensions but not in others. Overall, the results point to the interplay of several institutional, legal, and practical dimensions in generating and governing openness in CS projects.

In the cases sampled, CS digital platforms present features that allow to integrate community feedbacks throughout the project development process, which stresses both the value of participation beyond individual data collection (Phillips et al., 2019; Fuster Morell, 2010b) and the role of digital technologies in providing the setting for cultivating online communities of practice (Liberatore et al., 2018). Yet, the lack of a strong transdisciplinary formulation among the analysed projects aligns with current debates which call for broadening up the methodological spectrum and scope of CS beyond problem-focused natural sciences approaches (Tauginiene et al., 2020). Also, all the platforms sampled have a strong non-profit and pro-public character, and rely on a combination of funding sources which range from institutional support to private donations for favouring project's sustainability (Wiggins \& Crowston, 2014). However, all the studied projects seem to fall short in transparency for publicly displaying information about the type and redistribution of $t$ financial resources. Citizens-generated data, on the other hand, are widely accessible, albeit with restrictions in one of the cases (eBird), and usually associated with open licenses, which is a crucial element for favouring data access and reuse (Bowser et al., 2020). Also, the technological architecture of the projects sampled is mostly decentralized (except for eBird), and can be thus federated or connected to other platforms or initiatives, while the projects' software code is usually open source and available for modification by external developers. In this sense, as identified by previous studies, effective design and open infrastructures can facilitate the discoverability of CS projects, ease data management processes and improve projects' sustainability (Bowser et al., 2020).

Moreover, all the analysed projects except one (iNaturalist) support participants' access to published findings by disclosing the research articles generated through public participation, and all cases seem to play an important role in filling data gaps for environmental monitoring and reporting (eBird, Public Lab and Safecast), environmental awareness and education (iNaturalist), or by facilitating the creation of environmental infrastructure for biodiversity monitoring (GeoWiki), contributing this way to identify and address complex socio-environmental and sustainability problems (Sauermann et al. 2020). Evidence of derived policy impact, understood in terms of community resilience and reaction to the lack of actionable and reliable data provided by official bodies (Kenens et al., 2020; Dosemagen et al., 2011), seems especially relevant for those more open and community driven projects (Public Lab and Safecast), as compared to the rest of platforms that follow a crowdsourced participatory format. Finally, social responsibility is explicitly addressed in terms of participants privacy and digital rights in all but one platform (GeoWiki) through FAQs sections (iNaturalist, Safecast) and codes of conduct (eBird), in some cases collectively drafted (iNaturalist, Public Lab), which also inform about ownerships, privacy and provide practical guidelines for community engagement. Yet, there is no evidence of promoted initiatives or platform features that explicitly favour the inclusion of marginalized collectives, except for Public Lab which places a strong emphasis on empowering affected communities with tools and resources to discuss their environmental concerns. Also, none of the platforms sampled seems to clearly approach gender equality and awareness of care, contrary to debates in other online collaborative settings (Edelman \& Luca, 2014; Schor, 2014) which stress the importance of the gender dimension in online collaboration assessments, broadly linked to handling inclusion and diversity from an intersectional perspective.

Overall, our analysis points to the need and relevance of studying openness holistically at the governance, technological and impact levels in CS platforms and initiatives, which parallels similar efforts in other open and participatory domains. In this context, openness as opposed to enclosure or exclusion mechanisms, could be key for the coherent sustainability, accessibility and quality of scientific knowledge produced through citizens participation. CS can play, in this sense, an important role for the understanding of science as a 
commons, because (1) it can facilitate the integrated development of a multitude of projects with a great variety of scopes and participatory formats, (2) it can favour the constitution of self-regulated and polycentric governance and communication systems, while (3) it can also support conditions of distributed impact at the local level (Pelacho et al., 2021).

As already extensively discussed, CS represents a rather diverse, rapidly changing and complex phenomena characterized by a wide range of participatory formats, technologies in use and socialization opportunities (Eitzel et al., 2017; Kullenberg \& Kasperowski, 2016; Wiggins \& Crowston, 2014). It is also strongly embedded in network technologies which do play a role in shaping community interactions, information governance and knowledge access and redistribution (Newman et al., 2012). Therefore, in order to understand how CS communities of practice operate, how they have evolved and how they are likely to evolve in the future, further studies must take into account the digital culture and technological constraints of these virtual spheres, as well as the legal frameworks that regulate them. This preliminary adaptation of the framework, still open to discussion and refinement, aims to contribute to defining and understanding the conditions required for the sustainability, accessibility and quality of scientific knowledge produced through citizens participation in research-related initiatives, accounting for the sociotechnical and macrostructural factors influencing its design and coordination of participation.

\section{Limitations and future research}

The primary contribution of our study is the development of a framework for assessing the overlaps and entanglements between CS and CBPP. Yet, the exploratory nature of the framework's adaptation, the small sample size, and the reliance on information and data collected exclusively on the digital platform's features and public content available, do not allow for generalizability of the findings nor its representativeness. Future research should cover additional channels of communication of specific CS platforms, as well as interview and/or survey CS project leaders and community members, to gain a more deep understanding about the way platforms and projects are integrated and organized, how they operate internally and what outcomes or impact (in a wider sense) they generate. Future research could also apply new versions of this framework to the analysis and comparison of a greater variety of CS projects and models, to better capture the highly heterogeneous nature of CS practices (beyond digital mapping projects) and depict major trends and patterns. This would allow to validate or contrast these preliminary exploratory results, as well as the examined indicators, and capture clearer correlations among the commons' qualities considered in this study. Alternatively, such an approach could also be used to compare anecdotal CS and specific CBPP projects, to gain deeper insights on how CS and CBPP converge or, opposedly interesting, how they might differ. This could also serve as the basis for a more dynamic and quantitative approach, in which network analysis techniques could help to demonstrate the mentioned convergence or a differentiation of characteristics from a broader interrelated perspective and wider sample of cases.

\section{Funding}

The authors received no financial support for the research, authorship, and publication of this article.

\section{Declaration of conflicting interests}

The authors declare no conflict of interest. 


\section{References}

Aigrain P (2012) Sharing: Culture and the Economy in the Internet Age. Amsterdam University Press. DOI: 10.26530/OAPEN_409602.

Bauwens M (2007) The peer-to-peer revolution. Renewal: a Journal of Labour Politics 15(4), 25-37

Benkler Y (2002) Coase's Penguin, or, Linux and 'The Nature of the Firm'. The Yale Law Journal 112(3): 369. DOI: $10.2307 / 1562247$.

Benkler Y (2006) The Wealth of Networks: How Social Production Transforms Markets and Freedom. New Haven [Conn.]: Yale University Press.

Berti Suman A and van Geenhuizen M (2020) Not just noise monitoring: rethinking citizen sensing for risk-related problem-solving. Journal of Environmental Planning and Management 63(3): 546-567. DOI: 10.1080/09640568.2019.1598852.

Bowser A, Cooper C, Sherbinin A de, et al. (2020) Still in Need of Norms: The State of the Data in Citizen Science. Citizen Science: Theory and Practice 5(1): 18. DOI: 10.5334/cstp.303.

Bollier D (2008) Viral Spiral: How the Commoners Built a Digital Republic of Their Own. New York: New Press.

Bonney R, Cooper CB, Dickinson J, et al. (2009) Citizen Science: A Developing Tool for Expanding Science Knowledge and Scientific Literacy. BioScience 59(11): 977-984. DOI: 10.1525/bio.2009.59.11.9.

Bonney R, Phillips TB, Ballard HL, et al. (2016) Can citizen science enhance public understanding of science? Public Understanding of Science 25(1): 2-16. DOI: 10.1177/0963662515607406.

Castells M (1996) The information age. Oxford: Blackwell Publishers.

Castells M and Cardoso G (2006) The Network Society: From Knowledge to Policy. Washington, DC: Johns Hopkins Center for Transatlantic Relations.

Cooper C, Shanley L, Scassa T, et al. (2019) Project Categories to Guide Institutional Oversight of Responsible Conduct of Scientists Leading Citizen Science in the United States. Citizen Science: Theory and Practice 4(1): 7. DOI: 10.5334/cstp.202.

Crowston K and Howison J (2005) The social structure of free and open source software development. First Monday. DOI: 10.5210/fm.v10i2.1207. 
De Vries M, Land-Zandstra A and Smeets I (2019) Citizen Scientists' Preferences for Communication of Scientific Output: A Literature Review. Citizen Science: Theory and Practice 4(1): 2. DOI: 10.5334/cstp.136.

Del Savio L, Prainsack B and Buyx A (2016) Crowdsourcing the Human Gut. Is crowdsourcing also 'citizen science'? Journal of Science Communication 15(03): A03. DOI: 10.22323/2.15030203.

Dosemagen S, Warren J and Wylie S (n.d.) GRASSROOTS MAPPING- Public Laboratory. Available at: https://www.joaap.org/issue8/GrassrootsMapping.htm (accessed 26 February 2021).

Edelman BG and Luca M (2014) Digital Discrimination: The Case of Airbnb.com. ID 2377353, SSRN Scholarly Paper, 10 January. Rochester, NY: Social Science Research Network. Available at: https://papers.ssrn.com/abstract=2377353 (accessed 5 March 2021).

Eitzel MV, Cappadonna JL, Santos-Lang C, et al. (2017) Citizen Science Terminology Matters: Exploring Key Terms. Citizen Science: Theory and Practice 2(1): 1. DOI: 10.5334/cstp.96.

English PB, Richardson MJ and Garzón-Galvis C (2018) From Crowdsourcing to Extreme Citizen Science: Participatory Research for Environmental Health. Annual Review of Public Health 39(1): 335-350. DOI: 10.1146/annurev-publhealth-040617-013702.

European Citizen Science Association (2015). 10 Principles of Citizen Science. Available at: http://ecsa.citizen-science. net/sites/default/files/ecsa_ten_principles_of_citizen_science. Pdf (accessed 10 October 2020).

Fuster Morell M (2010a) Governance of online creation communities : provision of infrastructure for the building of digital commons. Thesis. Available at: https://cadmus.eui.eu//handle/1814/14709 (accessed 26 February 2021).

Fuster Morell M (2010b) Participation in online creation communities: Ecosystemic participation. In Conference Proceedings of JITP 2010: The Politics of Open Source, Amherst, MA, 6-7 May 2010 ,pp. 270-295. Amherst: ScholarWorks@UMass Amherst.

Fuster Morell M and Espelt R (2019) A Framework to Assess the Sustainability of Platform Economy: The Case of Barcelona Ecosystem. Sustainability 11(22): 6450. DOI: 10.3390/su11226450.

Fuster Morell M, Espelt R and Renau Cano M (2020) Sustainable Platform Economy: Connections with the Sustainable Development Goals. Sustainability 12(18): 7640. DOI: 10.3390/su12187640.

Fuster Morell MF, Salcedo JL and Berlinguer M (2016) Debate About the Concept of Value in Commons-Based Peer Production. In: Internet Science (eds F Bagnoli, A Satsiou, I Stavrakakis, et al.), Cham, 2016, pp. 27-41. Lecture Notes in Computer Science. Springer International Publishing. DOI: 10.1007/978-3-319-45982-0_3. 
Groom Q, Weatherdon L and Geijzendorffer IR (2017) Is citizen science an open science in the case of biodiversity observations? Journal of Applied Ecology Cadotte M (ed.) 54(2): 612-617. DOI: $10.1111 / 1365-2664.12767$.

Haklay M (2010) How Good is Volunteered Geographical Information? A Comparative Study of OpenStreetMap and Ordnance Survey Datasets. Environment and Planning B: Planning and Design 37(4): 682-703. DOI: 10.1068/b35097.

Haklay M (2013) Citizen Science and Volunteered Geographic Information: Overview and Typology of Participation. In: Sui D, Elwood S, and Goodchild M (eds) Crowdsourcing Geographic Knowledge: Volunteered Geographic Information (VGI) in Theory and Practice. Dordrecht: Springer Netherlands, pp. 105-122. DOI: 10.1007/978-94-007-4587-2_7.

Hess C and Ostrom E (2003) Ideas, Artifacts, and Facilities: Information as a Common-Pool Resource. Law and Contemporary Problems 66(1/2): 111-145. Available at: https://www.jstor.org/stable/20059174 (accessed 25 May 2021).

Irwin A (1995) Citizen Science: A Study of People, Expertise, and Sustainable Development. Environment and society. London; New York: Routledge.

Jasanoff S (ed.) (2010) States of Knowledge: The Co-Production of Science and Social Order. transferred to digital print. International library of sociology. London: Routledge.

Kelling S, Gerbracht J, Fink D, et al. (2012) A Human/Computer Learning Network to Improve Biodiversity Conservation and Research. AI Magazine 34(1): 10. DOI: 10.1609/aimag.v34i1.2431.

Kenens J, Van Oudheusden M, Yoshizawa G, et al. (2020) Science by, with and for citizens: rethinking 'citizen science' after the 2011 Fukushima disaster. Palgrave Communications 6(1): 58. DOI: 10.1057/s41599-020-0434-3.

Kieslinger B, Schäfer T, Heigl F, Dörler D, Richter A, Bonn A (2018) Evaluating citizen science - Towards an open framework. In: Hekler S, Haklay M, Bowser A, Vogel J and Bonn A (eds.) Citizen Science Innovation in Open Science, Society and Policy. London: UCL Press, pp.81-95.

Kloppenborg K, Ball M P, \& Greshake Tzovaras B (2021). Peer Production Practices: Design Strategies in Online Citizen Science Platforms. SocArXiv. DOI: 10.31235/osf.io/rw58y

Kosmala M, Wiggins A, Swanson A, et al. (2016) Assessing data quality in citizen science. Frontiers in Ecology and the Environment 14(10): 551-560. DOI: 10.1002/fee.1436. 
Kozinets RV (2010) Netnography: Ethnographic Research in the Age of the Internet. 1st ed. Thousand Oaks, CA: Sage Publications Ltd.

Kullenberg C and Kasperowski D (2016) What Is Citizen Science? - A Scientometric Meta-Analysis. PLOS ONE Dorta-González P (ed.) 11(1): e0147152. DOI: 10.1371/journal.pone.0147152.

Latour B (2007) Reassembling the Social: An Introduction to Actor-Network-Theory. Clarendon lectures in management studies. Oxford: Oxford Univ. Press.

Lessig L (2002) The Future of Ideas: The Fate of the Commons in a Connected World. 1. ed. New York, NY: Vintage Books.

Liberatore A, Bowkett E, MacLeod CJ, et al. (2018) Social Media as a Platform for a Citizen Science Community of Practice. Citizen Science: Theory and Practice 3(1): 3. DOI: 10.5334/cstp.108.

MacQueen KM, McLellan E, Kay K, et al. (1998) Codebook Development for Team-Based Qualitative Analysis. CAM Journal 10(2): 31-36. DOI: 10.1177/1525822X980100020301.

Madison MJ (2014) Commons at the Intersection of Peer Production, Citizen Science, and Big Data: Galaxy Zoo. ID 2495404, SSRN Scholarly Paper, 12 September. Rochester, NY: Social Science Research Network. Available at: https://papers.ssrn.com/abstract=2495404 (accessed 26 February 2021).

McKinley DC, Miller-Rushing AJ, Ballard HL, et al. (2017) Citizen science can improve conservation science, natural resource management, and environmental protection. Biological Conservation 208. The role of citizen science in biological conservation: 15-28. DOI: 10.1016/j.biocon.2016.05.015.

Mirowski P (2018) The future(s) of open science. Social Studies of Science 48(2): 171-203. DOI: 10.1177/0306312718772086.

Moreira S and Fuster Morell M (2020) Food Networks As Urban Commons: Case Study of a Portuguese “Prosumers” Group. Ecological Economics 177: 106777. DOI: 10.1016/j.ecolecon.2020.106777.

Newman G, Wiggins A, Crall A, et al. (2012) The future of citizen science: emerging technologies and shifting paradigms. Frontiers in Ecology and the Environment 10(6): 298-304. DOI: 10.1890/110294.

Ortega F, Gonzalez-Barahona JM and Robles G (2008) On the Inequality of Contributions to Wikipedia. In: Proceedings of the 41st Annual Hawaii International Conference on System Sciences (HICSS 2008), Waikoloa, HI, 2008, pp. 304-304. IEEE. DOI: 10.1109/HICSS.2008.333.

Ottinger G (2010) Buckets of Resistance: Standards and the Effectiveness of Citizen Science. Science, Technology, \& Human Values 35(2): 244-270. DOI: 10.1177/0162243909337121. 
Ostrom E (1990) Governing the Commons: The Evolution of Institutions for Collective Action. 1st ed. Cambridge University Press. DOI: 10.1017/CBO9780511807763.

Pelacho M, Rodríguez H, Broncano F, et al. (2021) Science as a Commons: Improving the Governance of Knowledge Through Citizen Science. In: Vohland K, Land-Zandstra A, Ceccaroni L, et al. (eds) The Science of Citizen Science. Cham: Springer International Publishing, pp. 57-78. DOI: 10.1007/978-3-030-58278-4_4.

Phillips TB, Ballard HL, Lewenstein BV, et al. (2019) Engagement in science through citizen science: Moving beyond data collection. Science Education 103(3): 665-690. DOI: 10.1002/sce.21501.

Resnik DB (2019) Citizen Scientists as Human Subjects: Ethical Issues. Citizen Science: Theory and Practice 4(1): 11. DOI: 10.5334/cstp.150.

Riesch H and Potter C (2014) Citizen science as seen by scientists: Methodological, epistemological and ethical dimensions. Public Understanding of Science 23(1): 107-120. DOI: 10.1177/0963662513497324.

Rose C (1986) The Comedy of the Commons: Custom, Commerce, and Inherently Public Property. University of Chicago Law Review 53(3). Available at: https://chicagounbound.uchicago.edu/uclrev/vol53/iss3/1.

Sauermann H, Vohland K, Antoniou V, et al. (2020) Citizen science and sustainability transitions. Research Policy 49(5): 103978. DOI: 10.1016/j.respol.2020.103978.

Schor JB, Fitzmaurice C, Carfagna LB, et al. (2016) Paradoxes of openness and distinction in the sharing economy. Poetics 54: 66-81. DOI: 10.1016/j.poetic.2015.11.001.

Senabre Hidalgo E and Fuster Morell M (2019) Co-designed strategic planning and agile project management in academia: case study of an action research group. Palgrave Communications 5(1): 151. DOI: $10.1057 / \mathrm{s} 41599-019-0364-0$.

Siefkes C (2011) The Emergence of Benefit-driven Production. In: OKCon, 2011.

Skarlatidou A, Suskevics M, Göbel C, et al. (2019) The Value of Stakeholder Mapping to Enhance Co-Creation in Citizen Science Initiatives. Citizen Science: Theory and Practice 4(1): 24. DOI: $10.5334 /$ cstp.226.

Strasser BJ, Baudry J, Mahr D, et al. (2018) "Citizen Science"? Rethinking Science and Public Participation. Science \& Technology Studies: 52-76. DOI: 10.23987/sts.60425.

Tauginienè L, Butkevičienè E, Vohland K, et al. (2020) Citizen science in the social sciences and humanities: the power of interdisciplinarity. Palgrave Communications 6(1): 89. DOI: 10.1057/s41599-020-0471-y. 
Theobald EJ, Ettinger AK, Burgess HK, et al. (2015) Global change and local solutions: Tapping the unrealized potential of citizen science for biodiversity research. Biological Conservation 181: 236-244. DOI: 10.1016/j.biocon.2014.10.021.

Wark M (2004) A Hacker Manifesto. Cambridge, MA: Harvard University Press.

Weber K, Pallas F and Ulbricht M-R (2019) Challenges of Citizen Science: Commons, Incentives, Organizations, and Regulations. The American Journal of Bioethics 19(8): 52-54. DOI: 10.1080/15265161.2019.1619862.

Weber S (2005) The Success of Open Source. Cambridge, Mass.: Harvard Univ. Press.

Whitehead NL and Wesch (2012) M Human No More: Digital Subjectivities, Unhuman Subjects, and the End of Anthropology. University Press of Colorado. Available at: https://www.jstor.org/stable/j.ctt4cgr5j (accessed 25 May 2021).

Wiggins A and Crowston K (2011) From Conservation to Crowdsourcing: A Typology of Citizen Science. In: 2011 44th Hawaii International Conference on System Sciences, January 2011, pp. 1-10. DOI: 10.1109/HICSS.2011.207.

Wiggins A and Crowston K (2014) Surveying the citizen science landscape. First Monday. DOI: 10.5210/fm.v20i1.5520.

Wiggins A, Bonney R, LeBuhn G, et al. (2018) A Science Products Inventory for Citizen-Science Planning and Evaluation. BioScience 68(6): 436-444. DOI: 10.1093/biosci/biy028. 